\title{
Los autistas de Fernand Deligny. Por una educación impolítica
}

Fernand Deligny's autists. In favor of an impolitical education

\author{
Mariana Chendo \\ mariana.chendo@usal.edu.ar \\ Universidad del Salvador. Argentina \\ Daniel Etchepare \\ lic.etchepare@gmail.com \\ Universidad del Salvador. Argentina
}

\section{Resumen}

Nuestro trabajo será una lectura de lo impolítico y lo imposible que nos lega Deligny, haciendo foco en las traducciones al castellano de Los Vagabundos Eficaces (1971) y Lo Arácnido y otros textos (2015). Retomaremos «lo impolítico» de la filosofía de Esposito y lo aplicaremos al ejercicio del desencuadre en Deligny. Recorreremos tres encuadres modernos: sujeto, proyecto, rendimiento; a cada uno de ellos le presentaremos un rasgo de Deligny: autista, arácnido, vagabundos eficaces. A lo largo de todos ellos intentaremos mostrar la comunidad autista de Deligny como acto impolítico a la educación moderna. Finalmente, nuestra apuesta será por una educación imposible, crítica radical a la representación moderna.

Palabras clave: Deligny; autistas; moderno; impolítico; sujeto; educación.

\section{Abstract}

We will try to read the concept of impolitic and impossible in Deligny's work. We will focus on Les Vagabonds Efficaces ("The Efficient Vagabonds", 1971) and The Arachnean and Other Texts (2015). We will return to "the impolitic" of Esposito's philosophy and try to apply it to the exercise of unframing in Deligny. We will work on three great modern frames: subject, project, achievement; to each of them, we will present a trait of Deligny: autistic, arachnid, effective vagabonds. Throughout them, we will try to show the autistic community of Deligny as an impolitic act to modern education. Finally, our bet will be for an impossible education, a radical critic to modern representation.

Keywords: Deligny; autists; modern; impolitic; subject; education

Cómo referenciar este artículo / How to reference this article:

Chendo, M. \& Etchepare, D. (2020). Los autistas de Fernand Deligny. Por una educación impolítica. Tendencias Pedagógicas, 35, pp. 49-61. doi: 10.15366/ tp2020.35.005 


\section{Él se quemará mirando al sol y es esta la bistoria del que espera para despertar. Vámonos de aquí. (Pescado Rabioso, A Starosta, el idiota)}

Yo bablo en otra lengua. (Fernand Deligny, La impostura)

\section{Presentación}

Fernand Deligny (1913-1996) sigue siendo una cuenta pendiente en la educación. El hombre raro al que no se puede presentar con diplomas, el hombre que ama los psiquiátricos, el profesor de niños inadaptados, el guía de retrasados e idiotas, el coordinador de redes arácnidas, el que no gusta ser llamado educador. El hombre breve de los aforismos, el hombre enigmático de los garabatos, el hombre que en 1937 empieza a acoger a niños inadaptados en las periferias de París, el hombre que durante la Segunda Guerra Mundial trabaja en el hospital psiquiátrico de Armentières, el hombre que propone fundar en Lille los primeros hogares de prevención de la delincuencia, el hombre que subvierte las jerarquías, que suprime las sanciones, que organiza salidas con los pacientes, el hombre que requisa los edificios destruidos por la guerra para alojar redes de niños a parte, el hombre que resiste las formas de la educación en una aldea con sus autistas ${ }^{1}$. Fernand Deligny no cabe, queda grande, queda ancho, queda afuera. Ese hombre raro que prefiere para sí la idea del poeta y del etólogo, como si educar tratase de seguir trazos y reinventar medios para ningún fin anticipable, capturable, representable.

Deligny desconcierta, desconciertan sus modos, desconcierta su estilo, nos desconcierta en nuestra condición de hombres modernos: hacedores de Planes, previsores de Objetivos, alistados a Estrategias, habitantes del Futuro, convencidos de la Ley, de la Igualdad, de la Unidad del Sujeto sujetado al gran Proyecto. Fernand Deligny (2017) dice que hay dos mundos: el de las fórmulas y el de lo que pasa «en todo momento aquí abajo» (14s.); lo que nos lega Deligny es lo que pasa aquí abajo como una crítica radical a toda representación moderna. Nos lega eso, garabatos, líneas, roturas, pedazos, su herencia es el legado de un trabajo de deconstrucción de la educación: podemos tomar todos los términos, todas las expresiones de nuestro vocabulario educativo y abrirlas; en su interior, encontraremos el vacío ${ }^{2}$. Deligny deconstruye la educación y la deconstruye con sus autistas: abre las categorías de la educación para mostrar que en su interior hay un vacío que escapa a la reducción representativa, provoca el colapso del orden simbólico y nos deja en las esquirlas. En tal sentido, la obra de Deligny es un acto impolítico. Si lo impolítico es el acto que «desfonda» la lógica de la política moderna (Espósito, 2006: 19ss.) ${ }^{3}$ mostrando la inautenticidad estructural de la política y su inadecuación para representar la comunidad o el individuo, entonces también Deligny — como Nietzsche, como Bataille, como Weil, Nancy o Agamben - es un pensador impolítico. Si la política moderna representa el Uno, el Bien, la Justicia, lo impolítico es el ejercicio del des: des-centramiento, des-construcción, des-encuadre, des-fonde, punto ciego de la perspectiva moderna. La obra de Deligny es el acto de des las categorías modernas en el ejercicio de liberar a la educación de su presunción representativa, liberarla del fin justo, del gran proyecto, del buen sujeto.

Toda vez que la educación sea imposible — y en Deligny lo es — surge el reconocimiento de la heterogeneidad radical de lo humano, imposible de reconducir a la unidad de una forma sin ejercerle violencia. La educación imposible en Deligny no nos lleva a dudar de que la educación suceda, nos lleva a la posibilidad de que suceda sin fin, sin proyecto, sin cálculo previsional posible. Desen-

\footnotetext{
${ }^{1}$ Cfr. Planella, J.: 2012.

2 Nos referimos al trabajo de deconstrucción que hace Deligny, leído en clave weiliana: «podemos tomar todos los términos, todas las expresiones de nuestro vocabulario político y abrirlas; en su interior encontraremos el vacío» (Weil, 2012, p. 111 , trad. C. Serratore).

${ }^{3}$ El concepto de «lo impolítico», utilizado por vez primera en 1918 por Thomas Mann en su texto Betrachtungen eines Unpolitischen, es retomado por Cacciari en L'impolitico nietzscheano de 1978. En los años 80, en línea deconstructiva, Roberto Esposito hace de «lo impolítico» una clave hermenéutica de la modernidad. A partir de entonces, «lo impolítico» es referencia obligada para toda crítica radical a la representación moderna. Cfr. Serratore (2017), Tatián (1994), Zagari (2009).
} 
cuadrar la educación para soportar el cuerpo desmembrado de lo social, comunidad ausente, inoperante, inconfesable, ejercicio parecido a ese susurro que acepta que «Dios se complace en utilizar los desechos, las piezas inútiles, los desperdicios...» (Weil, 1993, p. 44). La comunidad de autistas de Deligny, apartada a una aldea en Las Cevenas, puede acercarse tal vez a «la comunidad de muerte» batailleana, figura extrema de lo impolítico donde lo único por compartir es una falta - falta demasiado humana, falta de muerte- (cfr. Esposito, 2006).

Nuestro trabajo será una lectura de lo impolítico y lo imposible que nos lega Deligny poniendo el foco en las traducciones al castellano de Los Vagabundos Eficaces (1971) y Lo Arácnido y otros textos (2015). No intentamos más que una apuesta, recurriendo a la ayuda de la filosofía, en la forma del ensayo, a veces elíptico, muchas veces confuso. Finalmente, tal vez la elipsis y la confusión sean modos justos de recorrer ese enigma que Deligny nos hereda.

\section{Fernand Deligny impolítico}

«Yo amaba el psiquiátrico», dice Deligny, «lo amaba como es muy probable que mucha gente ame a alguien, decida compartir su vida con ese alguien» (Álvarez de Toledo, 2009, p. 12). Deligny tenía veinte años cuando fue por primera vez al psiquiátrico de Armentières; desde allí y hasta el final de su vida, amó esos jirones de humano que encontró en el psiquiátrico a sus veinte años. Jirones de bumano, vagabundos eficaces, niños colmados, redes arácnidas, presencias ligeras, autistas. Los documentos de Fernand Deligny son archivos antipsiquiatría —en su época y también ahora—, justamente porque Deligny amaba lo que sucedía en el psiquiátrico. Los documentos de Deligny no son archivos, son otra cosa, una escritura en jirones, no son documentos, son trazos errantes, dibujos, imágenes, escritura fragmentaria, rizomática pero entrecortada, sin cita, con anécdota, por momentos con la fluidez de quien ama, a veces con el tono angustiante de quien sabe que el tópos de lo amado no tiene lugar, sin categoría para la fragilidad, una modernidad sin lugar para los débiles.

Seguimos siendo modernos, hombres de progreso, devotos de un futuro que nos traerá todo lo que el pasado nos escatimó. Devotos del sujeto, sujetados al proyecto, proyectados a la indeterminación del futuro, seguimos siendo modernos. Modernos hombres rendidores, creyentes de lo uno, de lo idéntico, de la línea recta hacia la rectitud de una finalidad que nos traerá todo lo que el pasado no supo traernos. Educar para lo que el futuro esperará de nosotros, educar para extraviarnos en esas nuevas formas indeterminadas del progreso, educar para nuestro propio crecimiento, educar para una igualdad de la productividad del éxito, educar para la igualdad de todos y la completud de los iguales. Educar para, la educación para los fines del infinito buen sujeto. Si el fin justifica la educación, Deligny se aparta con sus autistas a las montañas en Las Cevenas. Porque Deligny no amaba el psiquiátrico, amaba lo que sucedía ahí adentro, no amaba el cerco, amaba el eso, amaba eso que sucedía ahí adentro, eso que se parecía al fracaso, a la posibilidad anulada, al pasado trunco, al presente ausente, a la frustración de futuro, eso que sucedía sin para y - a pesar de estar siendo sin ninguna finalidad - no cesaba en su suceso. Deligny no amaba el psiquiátrico, amaba el exceso de la trampa moderna, lo no querido por ninguno aunque explicado a la fuerza, lo que no cesaba de escapar a la razón del sujeto, los cuerpos derramados afuera de las categorías, los desbordes sin representación, los jirones de lo humano, la evidencia de los límites violentos de toda representación moderna. Si «la violencia es la rabia de querer reducir todo a lo idéntico» (Nancy, 2008, p. 28), la educación moderna es rabiosa y es violenta. Deligny se va a las montañas, se va a Las Cevenas con eso.

No es posible la grandeza del progreso. Deligny es de los que creen que no es posible la grandeza del progreso, no es posible sin pasar por el rasero del sujeto, el rasero del proyecto, el rasero de la buena finalidad del buen proyecto moderno. Deligny no amaba el psiquiátrico, amaba eso, lo que no puede sujetarse, lo que queda sin ligar a la ligadura moderna, esas existencias que prolongan hasta el final el abandono al que fueron condenadas en su mismo nacimiento. En 1970, Deligny decide que él habla otra lengua, la lengua de Janmari, la lengua desterrada de cualquier tierra moderna. En 1970, Deligny decide que él habla la lengua de sus autistas, la lengua de las ruinas de toda representación moderna. En 1970, Deligny se va a vivir con sus autistas a las montañas en Las Cevenas. «Pedagogía nómada» la llaman, «pedagogía poética», «pedagogía social», la extraña pedagogía a la deriva de un hombre raro. Si la condición de la educación es que sus prácticas sean universalizables, entonces la propuesta de Deligny es una educación imposible, una educación a la deriva.

¿Qué es eso que ama Deligny? ¿Qué son esas líneas, qué son esos trazos, esos dibujos errantes, 
divagantes, dispersos? ¿Qué es lo que nos quiere decir Deligny hablándonos esa lengua? ¿Por qué leer hoy, en nuestros tiempos de inteligencias y de artificios, a los autistas, a ese hombre raro, esas derivas y sus trayectos?

«Yo amaba el psiquiátrico», Deligny amaba el psiquiátrico porque amaba el suceso que excede las murallas, a pesar del encierro. Con mayor precisión, podríamos decir que lo que hace Deligny es una fenomenología del autista, pero no, porque el amor no tiene mayores precisiones y Deligny amaba el psiquiátrico. ¿Qué es esa pedagogía que nos lega Deligny, qué quiere decirnos? Pedagogía nómada, pedagogía poética, pedagogía divagante, el comunista exiliado del partido, el hombre raro, el maestro especial en París, el recogedor de las sobras en Armentières, en los hogares de Lille, en los barrios destruidos por la guerra, en la clínica La Borde, en la zona rural de Las Cevenas, el acompañante de los vagabundos errantes ¿qué es eso que hace Deligny, qué es lo que quiere legarnos? La retirada de Deligny con sus autistas a Las Cevenas es un acto de pedagogía impolítica, alejamiento que muestra el hueco de lo que queda distante, entregado «al reposo de lo incompleto, a la sombra de lo opaco, al silencio de la obra» (Esposito, 1996, p. 109).

Deligny amaba el psiquiátrico, pero no propone para sus autistas el lazo del amor, ni propone el lazo de inclusión al amparo de derecho, ni propone el pacto de civilidad a resguardo del Estado, ni propone ninguno de los subterfugios del gran relato moderno. Ni lo uno ni lo otro en una modernidad para la que la identidad es siempre sin diferencia. Ni representación ni tangente, Deligny elige la impostura que tiene lo impolítico, la impostura que incomoda todas las líneas del encuadre categorial y todas sus curvaturas, tensa el encuadre hasta mostrar que en el cuadro no cabe más de lo que el cuadro ya ha predeterminado para favor de sí mismo, para legitimidad de su propia perspectiva, de su verdad propia, de su propiedad auténtica. «Si los hombres deciden que sólo son semejantes entre sí, trazan una frontera: tienen en común una imagen de lo que son, imagen inveterada» ( $p$. 184). Si la modernidad es la época de la imagen del mundo y si la hipermodernidad es la época de la imagen sin mundo, entonces leer hoy a los autistas de Deligny es un acto impolítico que trae la posibilidad de «que lo humano esté más allá de esa frontera que proviene de una imagen» (p. 184), más allá de las murallas modernas. «La muralla; podría ser que se trate de la Institución o quizá también del Fuero Interno, de ese famoso soy. ¿Quién lo ha querido? El Rey. Hace largo rato que el Rey no reina más» (p. 122). Deligny se va a Las Cevenas, una impolítica comunidad autista en el reino moderno.

\section{Educar desencuadrar}

Buscando en las posibilidades de la lente una lengua equivalente a las formas autísticas, en 1955 Deligny escribe La Cámara instrumento pedagógico. Porque «es notorio que un niño autista no (nos) mira», porque hay una "fisura entre el punto de vista nuestro y el punto de ver de un niño autista», pero es también cierto y notorio que «esta fisura que evoco tiene lugar» (Deligny, 2005, p. 168). Truffaut, que en 1969 dirige Elpequeño salvaje, en 1975 produce Ese chico de abí, un documental lento, lírico e idealizado sobre Deligny y sus autistas en la red de Las Cevenas. El documental, que se convirtió en uno de los principales documentos antipsiquiatría de la época, es el contrapunto exacto del proceso de domesticación llevado a cabo por el Dr. Itard en el buen salvaje de Víctor.

En Elpequeño salvaje, el médico educador reconduce la extrañeza brutal del niño raro; el afecto de Itard hacia Víctor es proporcional a la violencia de la domesticación y a los intentos desesperados del buen educador por reducir el carácter extraño de ese niño natural. En todo caso, la riqueza y la pobreza de la educación disciplinante de El pequeño salvaje se juegan en el contenido del film, en la veracidad del relato, en su correspondencia con las correcciones institucionales. En Ese chico de abi, no. El contenido de Ese chico de abí no se comprende, no quiere comprenderse. Janmari, el encefalópata profundo, va y viene, errante, corta leña, se detiene, indiferente, desencuadrado. Si El pequeño salvaje es el montaje de las prácticas institucionales, Ese chico de abi es la apuesta impolítica a la forma institución. Si «la escuela y el cine como parte de los intentos de modernización de la cultura y la sociedad a comienzos del siglo XX [...] buscaron producir nuevos sujetos» (Serra, 2011, p. 12), si la emergencia del cine y la consolidación de la forma escolar comparten la historia de las subjetivaciones modernas, Deligny usa la cámara para mostrar la imposibilidad de subjetivar, el exceso demasiado real y siempre indeseable de la modernización, la fisura de la forma. Deligny usa el instrumento moderno contra sí mismo, filma las huellas que escapan al cálculo filmado, y las filma en desencuadre. Ese chico de abi es un acto impolítico, un acto contra toda perspectiva enfocada, planificada, 
encuadrada. Si El pequeño salvaje es muestra de las implicancias brutales de la ausencia de socialización, Ese chico de ahí es trazo de la exclusión salvaje de todo proceso identitario. La pregunta moderna que permite salir de la naturalización es pregunta por mirada y por imagen: ¿qué se ve al ver a un niño?, ¿qué se ve cuando decimos que hay un niño?, ¿qué se ve cuando se mira a un niño pero se piensa en los niños? (Frigerio, 2008). La modernidad es la época de la imagen del mundo, el mundo como representación. ¿Qué se ve al ver a un niño?, ¿qué permite pasar de la mirada de un niño al pensamiento los niños: qué permite pasar de ese chico de ahí a todo pequeño salvaje?, ¿quién ofrece la óptica? La respuesta moderna es «el orden simbólico» (id.). Deligny desencuadra la respuesta moderna y desencuadra la imagen y desencuadra la óptica: ¿qué ve un niño autista?, ¿qué podemos decir con lo que ve un niño autista?, ¿se puede pasar de la mirada errante de Janmari a la errancia de los autistas?, ¿se puede pasar de la humanidad errante del autista a la precariedad de la vida humana?, ¿pueden ser los autistas el más allá de la modernidad del sujeto, marca indicial de una olvidada simpatía por el hombre? La respuesta de Deligny es intempestiva, un no que es sí por ser no, una negatividad que detiene, que deja en demora, vacila, como un vagar a tientas: no es posible pasar de ese chico de ahí al pequeño salvaje, los autistas detonan el orden simbólico (2015); si educar es un proceso que permite pasar de un niño a los niños, del particular este al universal todos, entonces en Deligny la educación es imposible. Deligny habla otra lengua, la lengua del desencuadre autista, silencio impolítico.

Comolli y Sorrel (2016), en ese diccionario lúcido que es su estudio sobre cine, ubican a Deligny en el término «desencuadre» (p. 35). «Encuadrar equivale a decir con fuerza: esto es lo que conviene mirar, jesto es lo que es una mirada! ¡Esta es la buena imagen, el buen momento, el buen punto de vista!» (p. 137). La modernidad es un gran encuadre con sus instituciones como dispositivos encuadrantes y sus grandes relatos como perspectivas de encuadre único. Si la institución escolar no puede alcanzar la bondad del salvaje, en cualquier caso queda la institución de la casa o la institución especial o la institución del loquero; encuadre dentro de encuadre dentro de un monumental sistema de encuadres. En 1962, durante el rodaje de El gesto menor, la cámara de Josée Manenti intenta acercarse a dos autistas que están siendo seguidos por Deligny. Solo vemos líneas de errancia, «Yves, de verba tan rica, tan transgresora, tan curiosa, no se adapta en lo más mínimo al encuadre [...] Yves no se deja encuadrar. Se escapa al cuadro para seguir una aventura que también siempre se nos escapa» (p. 137). Fernand Deligny queda desencuadrado en la historia de la educación; llamándose a sí mismo «poeta y etólogo», nos aparece como pedagogo social, imposible hacerlo entrar en catálogo. La imposible educación de Deligny es una apuesta «no en el sentido de "educare" (educar-enseñar) sino de "e-ducere": salir, estar fuera, partir. Sostener la atención, caminar hasta el agotamiento, no querer llegar a "algo" [...] liberar la propia mirada $[\ldots]$ de cualquier prejuicio o destino prefijado» (Dussel, 2006, p. 19). Lo que nos traen los autistas de Deligny es el desencuadre de la figura del sujeto; su errancia autista nos trae el desencuadre del método; sus redes arácnidas, el desencuadre del proyecto; sus vagabundos eficaces, el desencuadre de una finalidad eficiente; lo que nos trae la comunidad de Las Cevenas no es la novedad de lo cierto, es lo impolítico de la real diferencia - siempre tan indeseable como insuprimible-, nos trae los límites del cuadro y el derrame del afuera. Si la perspectiva moderna equivale a decir con fuerza jesta es la buena imagen, el buen momento, el buen punto de vista!, iquédense aquí, adentro, no crucen el cerco, porque esta es la buena imagen moderna, la buena vista, el buen sujeto! Si la perspectiva moderna equivale al mundo de la perspectiva única y correcta, entonces los autistas de Deligny son el acto intempestivo del desencuadre, con lo intempestivo de un derrame mudo, un desborde errante, el exceso de la lengua de un constante desvío, vagando a tientas.

\section{Primer desencuadre: el sujeto}

«Tuve la oportunidad de ver actuar a niños llamados débiles mentales [...] desaparecen el sujeto y el objeto. Quedan la cosa y ese reflejo» (Deligny, 2015, p. 152). Butler (2006) acuña el concepto «vidas precarias» (p. 58) para denunciar la diferencia entre el desamparo original propio de la condición humana y el desamparo restrictivo de lo humano que se basa en la exclusión. Las vidas de los autistas de Deligny son precarias en ambos sentidos: en el original que señala la falta constitutiva de lo específico de ser bumano, pero también en el otro sentido de las existencias desamparadas por quedar desujetadas. Si la inclusión es una modalidad surgida de las tecnologías de poder de la modernidad, la exclusión se mantiene siempre a la sombra de las figuras inclusivas, siempre latente, siempre presen- 
te, siempre excluyente. El sujeto moderno sujeta con la absolutez de lo «unitario, autoconcentrado, racional, consciente de sí mismo» (Pineau, 1999, p. 40), tal es la fortaleza de los procesos de subjetivación, tal es la fortaleza de la identidad moderna. Lo disperso, lo radical heterogéneo, queda desligado, desujetado, al desamparo. "La mirada de la pedagogía sobre los alumnos es tributaria de esta noción moderna de sujeto [...] la modernidad convierte a la educación en el proceso por el cual el hombre se vuelve hombre, sujeto moderno» (Terigi, 2010, p. 13). Si ser humano en la modernidad es ser sujeto, entonces los autistas de Deligny no son humanos. Si la educación moderna es el proceso de subjetivación para hacer de lo humano un sujeto, entonces la educación de Deligny es imposible. «Janmari estaba ahí, con su punto de ver sensiblemente distante y diferente de nuestro punto de vista autónomo [...] Al leer que Janmari sería un sujeto que se identificaría con lo que fuera, [...] veo la indicación de la existencia de la $\mathrm{S}$ en el centro del sistema humano» (Deligny, 2015, p. 186). Ver vivir a Janmari trae a Deligny la convicción de que el autista «erra como un alma en pena privada del poder de identificarse con algUNO» (p. 188), el en-si-misma-miento del autista de Deligny es marca de la vacuidad del sí-mismo del sujeto moderno. Si los procesos de subjetivación modernos son tributarios de la absolutez del cogito cartesiano, entonces Janmari constata la imposibilidad del proceso identitario, la violencia siempre cruel y siempre hiriente de ser uno, ser sujeto y ser moderno.

La expresión sujeto de la educación ha sido empleada para identificar a quien aprende o está siendo educado: el sujeto pedagógico, el sujeto del aprendizaje, con todo el interés concentrado en los dispositivos institucionales, discursos, tradiciones familiares y sociales para la producción y la reproducción de las subjetividades identitarias (Cerletti, 2008, p. 40). El autista de Deligny está más allá del sujeto «más allá lo arácnido, [...] nosotros acá en los cristales» (2015, p. 43); las redes arácnidas son las redes autistas más allá de la cristalización de las subjetivaciones modernas; nosotros siempre en el acá de la forma y, más allá, los autistas, «lo amorfo [...] lo que no tiene forma cristalizada propia» (id.). El sujeto cartesiano es lo que Deligny llama «el hombre-que-somos»; con la frase «el hombre-que-somos» Deligny hace referencia a las trampas del sujeto, a los hombres entrampados en la representación, siempre una, idéntica a sí misma, inscriptora de los cuerpos en la identidad de su forma correcta.

Tratar la problemática del sujeto de la educación implica proponer un debate sobre las formas de producción de subjetividades, "pero también sobre el sentido y la crisis de la educación moderna» (Terigi, 2010, p. 14), en ese pero también del sentido y la crisis de la educación moderna se levanta el acto impolítico de Deligny contra el encuadre-sujeto. Antes de Descartes no había sujeto, «hace dos o tres siglos la filosofía occidental postulaba [...] la constitución de un sujeto que no está dado definitivamente, $[\ldots]$ un sujeto que se constituyó en el interior de la historia y que, a cada instante, es fundado y vuelto a fundar por ella» (Foucault, 1996: 8s.). Los autistas de Deligny son el «instante de peligro» del sujeto de la historia moderna (cfr. Benjamin, 1971, p. 79). Cuando las coacciones de la historia se hacen insoportables, advienen redes que rápidamente se descubren eficaces en el colmo de la historia, como punta de lanza; Deligny refiere a sus redes autistas, acto impolítico, punta de lanza contra la razón de la modernidad del sujeto. Si en la modernidad la educación es el proceso por el cual el hombre deviene sujeto, lo impolítico del acto de Deligny reside en habitar la modernidad sin su sujeto. El sujeto «desaparece, borrado, como se borra la idea de representar [...] se trata de exponer $[\ldots]$ más bien de acordar [...] más bien de una discordancia» (p. 154). Deligny no encuentra la palabra para el vacío de sujeto que es el autista: exponer, acordar, discordar, en cualquier caso, un representar distorsionado, liberado de la fijeza del encuadre sujeto. Si una educación impolítica fuese posible en las ruinas de los procesos de subjetivación, borraría la idea representativa de formar, se trataría más bien de ex-poner como sacar de centro, un descentrar que es desfonde. Si la educación impolítica de Deligny fuese posible, veríamos aparecer las fisuras de ese gran parche de identidad en que devino el sujeto.

Zizek (2014, p. 90; 2012, p. 324) compara la sustancia material de la conciencia de un autista con una casa deshabitada, la casa está vacía, el sujeto no está en ningún sitio. La mirada a eso —ni sujeto ni objeto-, la «dolorosa y perturbadora» mirada a eso, nos dará una idea del cogito cartesiano en su forma pura, en su «grado cero». En la mirada del autista, Zizek descubre el grado cero del sujeto de la modernidad. La perspectiva de Zizek es un estilo tan otro a la voluntad de Deligny, que la comparación entre sus autismos nos traería un collage obsceno; sin embargo, vale una nota en este acercamiento: la figura del autista es la punta de lanza contra el cristal del sujeto, mutismo impolítico que saca de cuadro al lenguaje moderno. 
«Esta es la experiencia fundamental: la desaparición del sujeto [...] lo que se gana es la ausencia, [...] lo desconocido, la ruptura del círculo semántico del saber» (Del Barco, 2008, p. 11). Los autistas de Deligny son una comunidad imposible en la representación moderna, pero pueden ser una comunidad impolítica en esta larga crisis del fundamento de la modernidad. Los autistas imposibles e impolíticos, trazos errantes de un espacio vacío anterior a la formación del sujeto, anterior y posterior a la formación del sujeto y del mundo, tan diaspóricos ante la exclusión como dispersos contra la inclusión identitaria; imposibles e impolíticos, los autistas como fisura constitutiva de una posible refundación de todo orden de saber; imposibles e impolíticos, los autistas de Deligny se parecen a lo que Derrida bautizó con el nombre de Khôra (Derrida: 1985-6), imposible espacio posibilitador de lo sido por venir.

«Al vivir cerca de niños autistas [...] se me hace manifiesto que hay dos libertades: la del sujeto, y [...] la otra libertad, que me parece en efecto que incumbe a la "memoria específica"» (Deligny, 2015, p. 164). Estamos los hombres-que-somos de sujeto y de derecho, nosotros los modernos, los sujetos sujetados que sujetamos para seguir ob-ligando. Pero está también eso que Deligny ex-pone, en un ex de la posición para sacar de cuadro, está también eso que Deligny expone, con la extrañeza de lo raro y la rareza de lo imposible. ¿Qué es eso? ¿Qué puede decirnos eso? Sin lenguaje. No hay territorialidad existente para la existencia autista. En tierras modernas, el autista siempre está desamparado, en esa migración constante y silenciosa que solo conocen los pueblos que trazan su diáspora. Rotas las tierras modernas, la comunidad de los autistas comunes con la guía de ese hombre raro puede marcarnos las huellas de una pedagogía de la fruición y el desvío, indicio de una nueva lengua.

Si ser educable es ser un animal influenciable (Antelo, 2005), entonces la educación en Deligny es imposible porque he allí el autista, ese animal sin influencia. La comunidad de Las Cevenas se parece al «pensamiento del afuera» que para Foucault (2000, p. 16) enuncia el fin de los límites del sujeto, haciendo brillar su dispersión sin obtener más que su irrefutable ausencia. Los autistas de Deligny son la exterioridad oculta en la identidad del sujeto, son el acontecer de lo real siempre indeseable pero siempre insuprimible, amorfos errantes, vagabundos eficaces, jirones de humano, los autistas de Deligny son la imposibilidad de la comunidad moderna, el sujeto derramado, el desborde de la lengua, cuerpos divagantes, desviados, ausentes, distantes, tentativas dispares sin ninguna influencia. Eso, ese chico de abí, son eso. ¿Qué es eso? ¿Qué sería educar sin el encuadre sujeto?

\section{Segundo desencuadre: el proyecto}

«Siempre hay, en algún lugar no se sabe dónde, una Corte Suprema que vela por los derechos [...], autistas como son, tienen derecho al proyecto pensado, [...] ¿pero qué pueden hacer con ese derecho, sino vivir en el desasosiego de divagar, que literalmente quiere decir: abandonar el camino? ¿De qué camino se trata? Del camino del proyecto pensado» (Deligny, 2015, p. 39). Lo que Deligny llama proyecto pensado tiene la estructura metódica de la certeza moderna, sostenida sobre el destierro calculado de cualquier experiencia. La expropiación de la experiencia está implícita en el proyecto fundamental de la ciencia moderna: para tener el valor de cierto, el conocimiento debe expropiar toda falibilidad de la experiencia. Lo que revela el proyecto pensado es que la verdad de la modernidad está en la certeza del método. Finalmente, la experiencia pierde todo valor con el triunfo de los instrumentos y los números: «una experiencia convertida en calculable y cierta pierde inmediatamente su autoridad» (Agamben, 2004, p. 155). Lo que importa no es la experiencia, sino la certeza, triunfo del máthema sobre el páthema, de lo calculable sobre lo soportable, del conocimiento sobre la experiencia, de la razón sobre los cuerpos, de la cifra sobre el acontecimiento. «Pero, para hacer esto, debe avanzar hacia una refundición de la experiencia y hacia una reforma de la inteligencia, expropiando antes que nada sus sujetos y poniendo en su lugar a un único nuevo sujeto» (ibid., 156). El proyecto pensado es imperativo y categórico, lo «absorbe todo, y lo que no puede absorber, lo destruye por inoportuno» (Deligny, 2015, p. 45). Por fuera del camino que es el método, queda el «vivir en el desasosiego del divague», abandonar el camino de la razón con su reflexión de cálculo. En este proyecto pensado, «afirmamos contar con una educación democrática, la realidad es muy diferente: tenemos un modelo educativo colonial [...] El objetivo principal de este modelo colonial es continuar discapacitando» (Chomsky, 2001, p. 10). El proyecto pensado promueve un modelo calculador-tecnocrático donde toda capacidad de transmisión viene indicada desde la precisión de 
las cifras. Tal es el motivo por el que Chomsky se refiere a estas capacidades como un proceso de discapacitación, donde se siguen datos para incorporar rutinas, recetas, reglas de intervención, que terminan haciendo del educador un buen burócrata repetidor de las ordenanzas proyectadas (Pérez Gómez, 1993: 11). El criterio de utilidad es la coronación del proyecto: sin importar «que el fruto del proyecto pensado sea horriblemente nocivo y venenoso» (Deligny, 2015, p. 42), hay que cumplir con su objetivo de utilidad y rendimiento.

La rapidez con que en el último siglo y medio ha avanzado el proceso de expropiación de la experiencia por la «cifra» es abrumante: de la sociedad del «conocimiento» a la sociedad de la «información» a lo que hoy podríamos llamar la sociedad del «dato» (cfr. Srnicek: 2018), sin detención, gustosos de ser seres de cálculo, devotos de la cifra por la cifra, adoradores de mediciones, repetidores de porcentajes, los hombres de la estadística. Desde sus inicios modernos en el cogito cartesiano hasta la certeza del big data en nuestra hipermodernidad, el proyecto calculador ha refinado sus mediciones, ha pulido los modos de su cifra, nos ha llenado de números a costa de cuerpos, de evaluaciones globales, de resultados sin experiencia. Ante el sosiego riesgoso de la instrumentalización, Deligny recoge a los inoportunos y se decide por el desasosiego del divague. Sus redes autistas son el desencuadre del proyecto calculador, su divague arácnido es el desencuadre de estas moscas que somos, atrapadas en los rincones del sistema. Hoy, en la desmemoria de una sociedad del dato y una única Red, las telarañas de Deligny son un acto impolítico que nos trae a recuerdo el enigma de la experiencia. «¿Dónde se encuentra el proyecto de la tela de araña? Dado que no se trata de un proyectopensado, desaparece la necesidad del proyecto [...] Donde emerge el dilema: proyecto pensado/arácnido» (Deligny, 2015, p. 40).

Retirados a Las Cevenas, la comunidad de autistas de Deligny tiene un doble trazo: muestra del triunfo del cálculo moderno pero, a la vez, experiencia que es puesta en incomodidad de los cercos del proyecto. «Las líneas que tenemos en la palma de la mano no estructuran la mano [...] los pliegues podrían muy bien distribuirse de otro modo [...]; dicho de otro modo, no tienen razón de ser. Así y todo su persistencia es notable; así sucede con lo arácnido» (Deligny, 2015, p. 80). Las líneas de la mano, los hilos derramados de una saliva autista, lo imposible de capturar en la representación moderna, va formando en Deligny ese enigma que es lo arácnido, reverso de toda previsión moderna. Las redes arácnidas que Deligny traza con lo «otro inoportuno» que el proyecto no pudo absorber son los trazos impolíticos que no podrán jamás corromper la continuidad del proyecto pero que, sin embargo, jamás cesarán de mostrar que en el encierro del cálculo solo es posible la supervivencia de una igualdad violenta sin nunca la diferencia. La comunidad de Deligny no es ningún riesgo para el proyecto, no se trata de una verdadera agresión, sin embargo los autistas de Las Cevenas son acto impolítico porque subestiman inquietantemente el proyecto moderno. Los actos autistas de Deligny no son en absoluto sublevados, sin embargo, en ellos se realiza la tragedia por debilidad y corrupción de la educación burguesa.

La práctica típicamente moderna, sustancial a la política moderna, esencial al intelecto moderno, propia de la vida moderna, «es el esfuerzo por exterminar la ambivalencia: un esfuerzo por definir precisamente» (Bauman, 2005, p. 27). Las líneas de errancia de los autistas de Deligny son el divague inoportuno de la vida moderna, sus trazos no queridos, su imposible ambivalencia, la potencial epidemia de los dispares dispersos ante la que «el poder organizado se exaspera haciendo limpieza, inventa escobas, multiplica los equipos de amas de casa» (Deligny, 2015, p. 29) para barrer las telarañas del proyecto. El «proyecto» es el lugar dominante de la educación (Bárcena, Larrosa y Mèlich, 2006), la palabra fetiche con todos sus complementos: «diseño, manipulación, ingeniería, regla, clasificación, orden y jerarquía [...] Desde esta mentalidad moderna, la única crítica legítima, pedagógicamente hablando, sería la que termina objetivándose en proyecto» (ibid., 234). El "proyecto» estructura el vocabulario de la educación: lenguaje de objetivos, planificaciones, estrategias, programas, evaluaciones, para que todo quepa en las cifras de nuestros cuerpos numéricos. La rapidez con que en los últimos años se ha afianzado el vocabulario del proyecto es abrumante, porque no solo se ha expropiado la experiencia sino que ahora ni tan siquiera se requiere la presencia de los cuerpos, cifrados virtuales que resignifican la «personalización» en el programa de un algoritmo.

Leer a Deligny hoy es un acto impolítico, porque sus trayectos autistas visibilizan lo pornográfico del proyecto hipermoderno: «las acciones se tornan transparentes cuando se hacen operacionales, cuando se someten a los procesos de cálculo, dirección y control $[\ldots]$ carentes $[\ldots]$ de todo sentido, se vuelven pornográficas» (Han, 2013, p. 11). Lo arácnido es inconmensurable, radical heterogéneo; y entonces eso, esos gestos que son Deligny, no pueden universalizarse. Sin embargo, su experiencia 
autista nos trae una comunidad de sentido, no para permitirnos proyectar sino para obligarnos a traer a memoria lo inconmensurable de la experiencia, la misteriosa singularidad de la fisura, los riesgos insanos de un proyecto que todo lo hace medible, todo comparable con todo, suprimiendo «cualquier rasgo de lo inconmensurable, cualquier singularidad de las cosas [...] un infierno de lo igual» (ibid., p. 12).

«Si gracias a esta práctica de trazar los trayectos aparece lo arácnido de las líneas de errancia, que son trazos de los pibes cuyo proyecto se nos escapa, ¿vamos a ser capaces de respetar como corresponde esa vecindad?» (Deligny, 2015, p. 45). Tal vez la experiencia autista de Deligny no nos traiga más que cierta incomodidad, quizá esos trazos inoportunos no nos traigan más que la inquietante extrañeza de la hospitalidad. ¿Corresponde respetar la vecindad de lo no-querido que desencuadra el proyecto? ¿Es posible encontrar debajo de nuestra bondad inclusiva la trampa calculadora del sujeto moderno?

\section{Tercer desencuadre: el rendimiento}

«En los umbrales de las chozas están sentados unos niños extraños, unos niños vomitados. No hay otra palabra para expresar su color y su forma» (Deligny, 1971, p. 175). Los Vagabundos Eficaces (1971) es la recolección de experiencias de Deligny en los diferentes centros de readaptación que dirige, centros abiertos a los inoportunos: vagabundos, inadaptados, indigentes, discapacitados, fugados, infames, todos ellos vomitados por las fauces calculadoras del proyecto moderno. Deligny se queda con los inoportunos, con los desbordes de la modernidad, con sus ruinas, con sus desastres. Vagabundos eficaces, «vagabundos tenaces [...] tan vivos que ninguna asistente social podría soportar...; unos desechos de hombres» (p. 179). Vagabundos eficaces a los que les repugnan los libros, asqueados de la monotonía cotidiana, «buscadores de lo absoluto» mientras nosotros estamos sujetados a la «esperanza de un mundo que sigue corriendo el riesgo de reventar de docilidad» (idem.). Los vagabundos eficaces de Deligny son la impostura de los débiles que permite desarmar los valores de las políticas de la eficiencia, de la formación para la utilidad, de la educación para la productividad del rendimiento.

Vagabundos eficaces. En su trabajo sobre la demarcación de los términos eficacia, eficiencia, equidad y sostenibilidad para definir las políticas sociales, Mokate (2001) escribe para el INDES y cita el María Moliner para el término eficacia: «eficacia se aplica a las cosas o personas que pueden producir el efecto o prestar el servicio al que están destinadas» (p. 2), unas líneas después, «un programa es eficaz si lograse los objetivos para que se diseñara», unas líneas después «una iniciativa resulta eficaz si cumple los objetivos esperados en el tiempo previsto con la calidad esperada». Esta última línea del después, le queda lejos la primera definición del María Moliner, que vinculaba el poder de la eficacia al destino: «el efecto al que están destinadas. En los giros de las líneas del término, Mokate enreda la palabra a la vuelta del proyecto: la eficacia está vinculada al diseño, los objetivos, la previsión y la calidad esperada — esperada por la modernidad del Banco y su desarrollo moderno, se entiende. «Nosotros entendemos que eficacia y efectividad son sinónimas y se pueden utilizar de forma intercambiable» (3), concluye Mokate en la plural tercera persona de la unidad del proyecto. La eficacia de ese «nosotros prematuro» que son los vagabundos de Deligny está hecha de tiempo sin previsiones, de esperas sin calidades, de errancias sin objetivos, de poderes destinales —el destino, se entiende, escapa siempre al diseño. Deligny llama a sus vagabundos eficaces en el exacto sentido en que el María Moliner define la eficacia: «personas que pueden producir el efecto al que están destinadas», Deligny habla de una eficacia que viene de mucho antes de la modernidad, una eficacia que la modernidad hereda para ocultar bajo el orden de su desarrollo, una eficacia que tiene que ver con la prepotencia tenaz de la vida (Deligny, 1971, p. 179), una eficacia que reconoce en la persona el poder de su destino.

Nosotros, con Deligny, entendemos que eficacia y eficiencia son opuestas y su uso intercambiable solo puede darse una vez hecha la trampa de la previsión moderna. «Una iniciativa resulta eficaz si cumple los objetivos» (Mokate, p. 2); «un programa es eficiente si cumple sus objetivos con el menor costo posible» (p. 5), he allí esa especificidad que es la eficiencia respecto de la eficacia moderna: en el menor costo posible. Se es eficaz si se cumple con los objetivos; se es eficiente si se es eficaz con el menor costo posible. La eficacia de los vagabundos de Deligny es un acto impolítico porque, con la misma categoría, interroga todos los términos del diseño. Los vagabundos impolíticos, porque su eficacia deprecia el valor de la eficiencia, deconstruye el valor con que el desarrollo da la vuelta para justifi- 
car el cálculo de su fundamento moderno. Los eficaces impolíticos, porque su vagabundeo pone en cuestión todo trabajo de cálculo con su familia de objetivos, diseños y evaluaciones por rendimiento.

Los vagabundos eficaces es un acto de impostura contra el valor del rendimiento. El hombre rendidor tardomoderno asume toda la carga semántica de la figura del trabajador moderno, en una asunción que es interiorización y valorización hiperpositiva donde el único factor que define la humanidad del hombre es la eficiencia con que desempeñe su función en la organización técnica de la que forme parte (Jünger, 1993). Eficiencia, flexibilidad, habilidades, competencias: lo que la educación entiende por siglo XXI es la formación para el siglo del rendimiento. Lo que Gert Biesta (2009) anticipa a principios de este siglo como conversión de la educación en aprendizaje, donde todo pasa a ser traducido en términos de aprendizaje, no es otra cosa que el dispositivo discursivo de la práctica del rendimiento, aprender a aprender es aprender para seguir rindiendo en el buen refinamiento de la educación para el trabajo: ser un buen aprendiz del siglo XXI es ser un útil rendidor a la productividad del proyecto. El hombre se reserva para sí el privilegio del proyecto pensado y «contempla con ojos conmovidos esas maravillas de ingenio y de utilidad que trabajan para él [...] obnubilado por la utilidad, que es la coronación del proyecto pensado» (Deligny, 2015, p. 46). El autista es «la prueba de lo que nos falta», dice Deligny después de haber escrito con ironía penosa sobre el trabajo útil del proyecto moderno. El autista es la prueba de lo que nos falta, porque la «voluntad ya ha realizado el salto peligroso [...] la voluntad ya ha abandonado el firme apoyo del ser, ya se ha arrojado en el vacío» (49). La eficacia de los vagabundos eficaces está en haber saltado del sujeto, liberada la voluntad de poder, liberado el «quantum de fuerza, de pulsión, de voluntad, de actividad, sin ser nada más que ese mismo pulsionar, ese mismo querer, ese mismo actuan» (Nietzsche, 2001: 59). Lo que nos falta a nosotros, los hombres-que-somos, es la tenacidad de la vida, el destino de la eficacia, la prepotencia de la voluntad, el arrojo de la vagancia. Si la eficiencia de la educación justifica la destinación de su eficacia, entonces la propuesta de Deligny es una educación imposible.

«Podría volver cien veces sobre la manera en que una red crece y cien veces retocar la leyenda del pan, de ese pan que se hace aquí, una suerte de capricho vernáculo nacido del encuentro» (Deligny, 2015, p. 117), Deligny vuelve a la leyenda del pan en la aldea de Las Cevenas, el trabajo nacido de sus errantes, con tenacidad eficaz y el ritmo de un ritual, el pan como acto impolítico para mostrar la banalidad del rendimiento. «Uno puede sorprenderse de que haya a menudo coincidencia entre el trabajo bien hecho y la actitud, el tono de voz, las maneras» (p. 117), impolítica hospitalidad vernácula que socaba la indiferenciación del rendimiento. Deligny cita poco, entre ese poco, cita a Illich con el valor de lo vernáculo y El trabajo fantasma (p. 106); no porque crea que la lengua vernácula corresponde a sus autistas — sus autistas son de otra lengua, ni vernácula ni materna, son de una lengua que rompe la lengua moderna-, sino porque es necesaria una palabra simple, directa, que califique las acciones fuera del mercado moderno. Pero esa palabra no existe, queda el olor del pan, quedan los gestos.

«¿Educadores? ¿Quiénes sois? Formados en ayudantías o en cursos nacionales o internacionales, instruidos sin ninguna preocupación previa de saber si tenéis en la barriga un mínimo [...] de simpatía hacia el hombre» (Deligny, 1971, p. 110). La pedagogía de la errancia en Deligny es una pedagogía imposible, no puede explicarse, no puede volverse método de norma ni estrategia de práctica, no puede catalogarse, Deligny habla otra lengua, incapturable en el cristal del discurso, la lengua de las esquirlas modernas, educación para nada en favor de los nadies, como el reflujo ácido de un mundo indigesto de tanto éxito y eficiencia. La educación de Deligny es imposible porque imposible es saber si nos cabe en la barriga un mínimo de simpatía hacia el hombre.

Aprender para un futuro incierto, formar para la utilidad, innovar para la producción, crear para el éxito, educar para el futuro de trabajos que aún no existen, competir con la inteligencia artificial, personalizar los sistemas complejos, capacitarnos para flexibilizarnos, flexibilizarnos para adaptarnos, adaptarnos para caber, caber para hacer, hacer para seguir, seguir para ser útiles, ser útiles para producir, producir para ser exitosos, ser exitosos para caber, caber para hacer, hacer para seguir. En el umbral del proyecto, a la sombra del sujeto, en la errancia de ese gran programa que es la eficiencia, siguen sentados los niños extraños, autistas vomitados, vagabundos eficaces. «A este(a) advenedizo(a) desamparado(a), ¿qué decirle?» (Deligny, 2015, p. 116).

¿Qué decirnos? ¿Qué hacer con tanta ruina moderna? ¿Educadores? ¿Quiénes somos? 


\section{Guarda el hilo nena \\ Guarden bien tus manos \\ Esta libertad \\ (Pescado Rabioso, Cantata de puentes amarillos)}

«Yo hablo en otra lengua.» Deligny habla en otra lengua, una lengua más allá del umbral de la lengua, habla la lengua de las esquirlas. Deligny habla desde el destierro de la lengua moderna, nos habla a nosotros, los bien terrados. Deligny escribe las líneas de errancia de sus autistas, dibuja los mapas de sus vagares, imposibles, imposibles las líneas, imposible los mapas, imposible la lengua. Lo escribe para nosotros, los bien hablantes, los bien pensantes, los bien sujetos. ¿Qué quiere decirnos Deligny?, ¿qué entender de la lengua imposible de los autistas?, ¿qué son esos mapas, qué son esas líneas, qué son esos trazos, divagantes, ambiguos, errantes? «Y lo humano aparece entonces como lo que queda, un poco en jirones» (2015, p. 269), tal es la frase que precede los «Mapas y leyendas» de los trazos autistas: «los desplazamientos de tres niños autistas durante la preparación del pan» y la imagen es imposible; «los desplazamientos de un niño autista entre la cocina y el comedor (a la izquierda) y en el jardín (a la derecha)» y la imagen que acompaña es imposible, sin saber cuál es la izquierda y cuál la derecha, igual la cocina al comedor que al jardín. Deligny nos lega los trazos. ¿Qué son esos trazos? ¿Qué quiere decirnos Deligny? Deligny habla otra lengua. En 1970, Fernand Deligny lleva a cabo la primera tentativa de creación de una red arácnida, hecha de los hilos errantes de niños autistas, en Las Cevenas. La red arácnida se teje a partir de Janmari, a partir de su modo de ser fuera del lenguaje. Deligny habla otra lengua, la lengua de Janmari. Lo que hace Deligny es ir a la deriva, contra toda permanencia institucional, el hombre de los raros va a la deriva. Si para que una serie de prácticas pueda convertirse en educación hace falta que sean universalizables, entonces la propuesta de Deligny es una educación imposible, educar a la deriva. Pero ahí está lo que hace y ahí está la metáfora de lo que hace: «una balsa [...] unos troncos de madera atados entre ellos de tal forma que quedan bastante sueltos, de modo que cuando les caen encima montañas de agua, el agua pasa a través de los troncos separados» (Álvarez de Toledo, 2009, p. 43), ahí está lo que Deligny comprende que es la educación, una balsa, «estructura rudimentaria [...] Cuando llueven los interrogantes, nosotros no cerramos filas - no juntamos los troncos- para constituir una plataforma bien concertada» (idem.). Si para que una serie de prácticas pueda convertirse en educación deben constituir un modo, ahí está el modo de ese hombre raro: «Podéis ver así la importancia primordial de los vínculos y del modo de atadura, y de la distancia que los troncos pueden tener entre sí. El vínculo tiene que ser lo bastante suelto y que no se suelte» (id.). En Cuando el hombrecito no está (2005, p. 247), Deligny vuelve a la imagen de la balsa, cuando las «grandes modas nos caen encima, nos pasan de largo [...] las convicciones, de donde sea que vinieran, pasan cruzando el piso». La balsa no es más que una tentativa (ibid., p. 88); en una carta de 1976, Deligny explica a Althusser qué es lo que él trata de hacer con esos niños «en quienes la hominización ha errado el tiro»: solo una tentativa, si algún aspecto político tiene una tentativa, «diré que un procedimiento así está al margen de los aparatos ideológicos del Estado: una pequeña banda se organiza lo mejor que puede y persiste a pesar de todo [...] una tentativa [...] es un nosotros prematuro» (Álvarez de Toledo, 2009, p. 102). Una tentativa y una balsa, he allí la imposible educación de Deligny. En $A$ propósito de los lugares que matan (2015), Asun Pié Balaguer trae en la pedagogía de Deligny la idea de evasión, un constante esquivar, una errancia que hace necesario un territorio abierto, infinito, sin límites, no moderno. Si la modernidad es la época de la imagen del mundo y si la hipermodernidad es la imagen sin el mundo, Deligny habla otra lengua. Si la imagen moderna — con mundo o sin él- es imagen de los fuertes, todos ellos útiles productivos, entonces Deligny habla roturas, habla pedazos, habla fragmento.

«Cuando la función simbólica se detona, guarda con las esquirlas», aconseja Deligny (2015, p. 147). «Guarda con las esquirlas» es casi una amenaza, casi el único momento que hace explícito ese instante de peligro para la educación moderna que son sus autistas. Los autistas de Deligny son un acto de educación impolítica porque detonan toda función simbólica y hay que cuidarse de las esquirlas. Leer hoy a Deligny es un acto impolítico porque nos habla a los muchos que aún creemos que la educación está hecha de gestos y tentativas, los muchos que aún apostamos a ese espacio misterioso que es el aula y que María Zambrano (1986) compara con un claro de bosque: «no hay 
que ir a buscarlos, ni tampoco buscar nada en ellos, nada determinado, prefigurado, consabido», nos habla a los que creemos que transmitir tiene el carácter de un don generoso, los impolíticos que aún creemos que la educación es un hecho político que hay que habitar con los cuerpos siempre inconmensurables, siempre excesivos, siempre derramando afuera, los que creemos que educar tiene más que ver con el azar de los hilos de una saliva autista que con los datos calculados para premeditación de un programa, los que creemos que la única promesa de futuro está anclada en la memoria, los que sabemos que todo nosotros es prematuro y es errante, nos habla a nosotros los que seguimos teniendo en la barriga simpatía por el hombre. En todo caso, las esquirlas nos traerán lo humano en jirones. Los humanos, demasiado humanos de Deligny horadan las utopías de la inteligencia, horadan las distopías de la máquina, horadan desde la memoria de especie de una existencia autista. Encontrar en los trayectos autistas el camino para desandar las tramas del artificio que es la educación moderna, tal la impostura política de volver hoy a Deligny. En todo caso, en estos tiempos en que la clausura ha adoptado la inmensidad de la Red, las redes arácnidas de Deligny nos recuerdan que las almas repudian todo encierro, que hay que guardar los hilos, guarden bien las manos esta libertad.

\section{Referencias}

Agamben, G. (2004). Infancia e historia. Buenos Aires: Adriana Hidalgo.

Álvarez de Toledo, S. (2009). «Presentación» en Deligny, Fernand. Permitir, trazar, ver. Barcelona: Museu d'Art Contemporani de Barcelona, pp. 5-16.

Bárcena Orbe, F., Larrosa Bondía, J. y Mèlich Sangrá, J. C. (2006). «Pensar la educación desde la experiencia» en Revista portuguesa de pedagogía. Año 40-1, pp. 233-259.

Bauman, Z. (2005). Modernidad y ambivalencia. Barcelona: Anthropos.

Benjamin, W. (1971). Angelus novus. Barcelona: Edhasa.

Berbert, M. y Truffaut, F. (1970). L'Enfant sawvage. Francia: Les Filmes Du Carrosse.

Biesta, G. (2009). Good education in an age of measurement: on the need to reconnect with the question of purpose in education. Educational Assessment, Evaluation and Accountability, 21 (1), 33-46. doi: doi.org/10.1007/s11092-008-9064-9.

Butler, J. (2006). Vida precaria. El poder del duelo y la violencia. Buenos Aires: Paidós.

Cacciari, M. (1994). «Lo impolítico nietzscheano» en Desde Nietzsche. Arte, tiempo y política. Buenos Aires: Biblos, pp. 61-79.

Cerletti, A. A. (2008) Repetición, novedad y sujeto en la educación. Un enfoque filosófico y politico. Buenos Aires: Del Estante.

Chomsky, N. (2001). La deseducación. Barcelona: Gedisa.

Comolli, J. L. y Sorrel, V. (2016). Cine, modo de empleo. De lo fotoquímico a lo digital. Buenos Aires: Manantial.

Del Barco, O. (2008). «Leer a Blanchot» en Blanchot, M. La ausencia del libro. Nietæsche y la escritura fragmentaria. Edición digital disponible en https://audiocreativa.files.wordpress.com/2017/03/118431905-nietzsche-y-la-escriturafragmentaria.pdf (consultado 13-3-2019).

Deligny, F. (1971). Los Vagabundos Eficaces. Barcelona: Estela.

Deligny, F. (2015). Lo Arácnido y otros textos. Buenos Aires: Cactus.

Deligny, F. (2017). Semilla de crápula. Buenos Aires: Cactus.

Derrida, J., «Khôra, nomos, topos, logos», séminaire à la Sorbonne. Cours 1985-6. Archivo Derrida. IMEC-ARCHIVES, DRR 175.

Dussel, I. y Gutiérrez, D. (2006). Educar la mirada: politicas y pedagogía de la imagen. Buenos Aires: Manantial.

Esposito, R. (1996). Confines de lo politico. Madrid: Trotta.

Esposito, R. (2006). Categorías de lo Impolítico. Buenos Aires: Katz. doi: doi.org/10.2307/j.ctvm7bf02.

Foucault, M. (1996). La verdad y las formas jurídicas. Barcelona: Gedisa.

Foucault, M. (2000). El pensamiento del afuera. Valencia: Pre-Textos.

Frigerio, G. (2008). La división de las infancias. Buenos Aires: Del Estante.

Han, B. C. (2013). La sociedad de la transparencia. España: Herder.

Jünger, E. (1993). El trabajador. Barcelona: Tusquets.

Mokate. K. (2001). «Eficacia, eficiencia, equidad y sostenibilidad: ¿Qué queremos decir?» Documento 
de trabajo I-24. Washington D. C. Banco Interamericano de Desarrollo. Recuperado de: https://publications.iadb.org/bitstream/handle/11319/1193/Eficacia $\% 2 \mathrm{c} \% 20$ eficiencia $\% 2 \mathrm{c} \% 2$ 0equidad $\% 20 \mathrm{y} \% 20$ sostenibilidad $\% 20 \% \mathrm{C} 2 \% \mathrm{BFqu} \% \mathrm{C} 3 \% \mathrm{~A} 9 \% 20$ queremos $\% 20 \mathrm{decir} \%$ $3 \mathrm{f} \% 20 \% 28 \mathrm{I}-24 \% 29$.pdf? sequence $=1$ \&isAllowed $=\mathrm{y}$.

Nancy, J. L. (2008). «Tres fragmentos sobre nihilismo y política». En: Nibilismo y Política, compilado por R. Esposito, C. Galli y V. Vitiello. Buenos Aires: Manantial, pp. 15-34.

Nietzsche, F. (2001). La genealogia de la moral. Madrid: Alianza Editorial.

Planella, J. (2012). «Fernand Deligny. Pedagogía y nomadismo en la educación de las otras infancia» en Educació i Història: Revista d'Història de l'Educació, Núm. 20 (juliol-desembre), pp. 95-115.

Pérez Gómez, A. I. (1993). «La función y formación del profesor/a en la enseñanza para la comprensión. Diferentes perspectivas.» en Gimeno, J. y Pérez, A. I. Comprender y transformar la enseñanza. Madrid: Morata, pp. 398-429.

Pié Balaguer, A. (2015). «A propósito de los lugares que matan» en Pié Balaguer, A. y Solé Blanch, J. (coord.) Escenas de educación social. Barcelona: Editorial UOC, cap. 9.

Pineau, P. (1999). «Premisas básicas de la escolarización como construcción moderna que construyó la modernidad» en Revistas de Estudios del Curriculum, 2 (1), pp. 39-61.

Serra, M. S. (2011). Cine, escuela y discurso pedagógico. Articulaciones, inclusiones y objeciones en el siglo XX en Argentina. Buenos Aires: Teseo.

Serratore, C. (2017). «Lo impolítico en el pensamiento de Roberto Esposito» en Soft Power, volumen 4, número 2, julio-diciembre, pp. 292-314.

Servolin, I. y Deligny, F., Manenti, J., Daniel, J. P. (1971). Le Moindre Geste. Francia: SLON.

Srnicek, N. (2018). Capitalismo de plataformas. Buenos Aires: Caja Negra.

Tatián, D. (1994). «Implicación política de la recepción heideggeriana de Nietzsche» en Nombre: Revista de Filosofía, Año IV, Número 5, noviembre, pp. 37-48.

Terigi, F. (2010). Sujetos de la Educación. Buenos Aires: Ministerio de Educación de la Nación.

Victor, R. y Deligny, F. (1975). Ce gamín, là. Francia: Les Filmes Du Carrosse.

Weil, S. (1992). «Non ricominciamo la guerra di Troia» en G. Gaeta, Simone Weil. San Domenico di Fiesole: Edizioni Cultura della Pace.

Weil, S. (1993). A la espera de Dios. Madrid: Trotta.

Zagari, A., Gercman, B., González, A. (2009). Roberto Esposito, tres ensayos sobre una teoría im-politica. Buenos Aires: Ediciones del Signo.

Zambrano, M. (1986). Claros del bosque. Barcelona: Seix Barral

Zizek, S. (2012). Viviendo en el final de los tiempos. Madrid: Akal.

Zizek, S. (2014). Acontecimiento. Madrid: Sexto Piso. 